\title{
Detection of cervical intraepithelial neoplasia (CIN) by visual inspection of cervix with acetic acid (VIA) and its comparison to cervical cytology
}

\author{
Nargis Zahan, ${ }^{1}$ Mosammat Nargis Shamima, ${ }^{2}$ Sharmin Sultana, ${ }^{3}$ Mohd. Alamgir Hossain ${ }^{4}$
}

\begin{abstract}
Background: Cervical cancer is the second most common cancer in women throughout the world, and it is the leading cause of cancer death among women in underdeveloped countries like Bangladesh is preventable and curable if detected at and early stage using proper screening tools. This study was done to see the effectiveness of VIA and find out the CIN and introduce as a complementary to cytology for diagnosing precancerous form of cervix.
\end{abstract}

Materials \& Methods: A total 175 subjects were studied \& relevant data of cervix related patients have been collected. The data regarding Pap smear, VIA and biopsy have been taken and collected data was analysis by SPSS.

Results: Out of 175 Patients VIA positive 53 (30.3\%), Pap smear reports, 84 (48.0\%) had inflammatory findings and $38(21.7 \%)$ had dysplasia and biopsy result $41(23.4 \%)$ CIN positive. Sensitivity of VIA was $90.2 \%$, specificity $88.1 \%$, PPV $69.8 \%$, NPV $96.7 \%$ and accuracy $88.6 \%$. Sensitivity of Pap smear reports was $80.5 \%$, specificity $96.3 \%$, PPV $86.8 \%$, NPV $94.2 \%$ and accuracy $92.6 \%$.

Conclusion: Visual inspection of cervix after application of acetic acid (VIA) is valid as cytology test for the identification of pre-invasive cervical cancer (CIN). Thus VIA is a useful screening method of Cervical Intraepithelial Neoplasia lesion as Pap smear.

Key Words: VIA, Pap smear, Biopsy

TAJ 2018; 31: No-1: 15-20

\section{Introduction}

Cervical cancer is the second most common cancer in women throughout the world, and it is the leading cause of cancer death among women in underdeveloped countries. The incidence and mortality rate of cervical cancer have markedly decreased in developed countries since cytological cervical cancer screening was introduced more than 50 years ago. ${ }^{1}$ PAP smear is a simple, safe, non-invasive and effective method for detection of pre-cancerous, cancerous and non-cancerous change in the cervix. ${ }^{2}$ Recently, non-cytology based screening methods such as visual inspection of cervix with acetic acid (VIA) is of particular interest especially to developing countries because it is inexpensive, only require supplies usually locally obtainable, immediate feedback of the test result to the patient and treatment can be provided. ${ }^{3}$ Bangladesh has a population of 50.19 million women ages 15 years and older who are at risk of developing cervical cancer. ${ }^{4}$ As cervical cancer is a major health problem among the

1 Junior Consultant, Department of Obstetrics \& Gynaecology, Rajshahi Medical College Hospital, Rajshahi.

${ }^{2}$ Assistant Professor, Department of Obstetrics \& Gynaecology, Rajshahi Medical College, Rajshahi.

${ }^{3}$ Medical Officer, Department of Obstetrics \& Gynaecology, Rajshahi Medical College Hospital, Rajshahi.

${ }^{4}$ Assistant Professor, Department of Orthopaedic Surgery, Rajshahi Medical College, Rajshahi. 
women of Bangladesh needs screening programme at the national level that identified it's at precancerous stage and if treated successfully, the lesion do not develop into invasive cancer. As Bangladesh is a low resource developing country needs a suitable screening test that should have cost benefit, acceptability, repeatability \& validity (sensitivity \& specificity). Visual Inspection of cervix with acetic acid performed by field level be a feasible method for screening cervical cancer in the present socio-economic context of Bangladesh as it fulfills all the criteria of an ideal screening method. Besides this, emphasis was also given on the community involvement \& motivation by developing awareness of screening test.

This study was done to see the effectiveness of VIA and find out the efficacy of this procedure in detecting cervical intraepithelial neoplasia (CIN) and introduce as a substitute or complementary to cytology for diagnosing precancerous form of cervix.

\section{Materials and Methods}

In this Cross Sectional comparative study carried out 175 women of age group between 20-55 From July 2011 to June 2013 of Outpatient Department of Obstetrics and Gynecology, Rajshahi Medical College Hospital, Rajshahi. Data have been collected from the respondents as per pre-tested data collection sheet by face to face interview after taking prior informed consent from them. Pattern Of Patients Characteristics : Age, Education, Occupation, Marital status, Age of $1^{\text {st }}$ marriage, Duration of marriage (years), Parity, Contraception, Past history of STD, Husband's history of past STD, Complaints of whitish discharge, itching, post coital bleeding, post menopausal bleeding. Method Of Cytology, Via \& Biopsy: The patient were asked to evacuate bladder and lie down on the examination table in modified lithotomy position then per speculum examination of cervix and vagina was done. After removing excess discharge the squamocolumner junction was visualized with the hooked end of Ayre's spatula squamocolumnar junction was scraped gently and rotated 360 degree twice to obtain a sample has been prepared across glass slide by spreading the specimen and fixed immediately in 95\% ethyl alcohol and stained by Papanicolaou stain, the Paps slides were read by cytologists using Bethesda system, pap smears showing -CIN, ASC-US, ASC-H, invasive cancer. Then method of VIA- the patients were explained about VIA procedure, then cervix was painted with gauze swab soaked with $5 \%$ acetic acid and reinspected by naked eye after 1 minute. VIA will be considered +ve if demarcated acetowhite lesions visualized close to the transformation zone In the cervix. Finally, biopsy was taken all cases with the help of cervical punch biopsy forcep. The tissues were then fixed with $4 \%$ formalin, leveling properly and sent to the pathology department of Rajshahi Medical College laboratory. Abnormalities outside the transformation zone considered negative. Biopsy with features of HPV, CIN, AIS or glandular dysplasia were considered +ve. Results were than complied and analyzed, sensitivity, specificity, positive predictive value (PPV), negative predictive value (NPV) and accuracy was than calculated for Pap Smear, VIA and compared with that of gold standard biopsy result.

\section{Results}

Total 175 subjects were studied in Outpatient Department of Obstetrics and Gynecology, Rajshahi Medical College Hospital. The relevant data regarding Pap smear, visual inspection of cervix with acetic acid (VIA) and biopsy have been taken and collected data was tabulated for findings convenient results. The observation and findings about the Age, P/S finding of cervix, VIA, cytology and biopsy and desired outcome have been shown in different tables and figures. The age distribution of 175 patients subjects is shown in table-I.

Table I: Age distribution of the subjects ( $\mathrm{n}=175)$.

\begin{tabular}{cccc}
\hline Age (yrs.) & frequency & \multicolumn{1}{l}{$\%$} & Mean \pm 2SD \\
\hline $20-25$ & 12 & 6.9 & \\
$26-30$ & 45 & 25.7 & \\
$31-35$ & 29 & 16.6 & \\
$36-40$ & 33 & 18.8 & $(36+2 \times 8.0)$ \\
$41-45$ & 34 & 19.4 & $=36 \pm 16.0$ \\
$46-50$ & 15 & 8.6 & \\
$51-55$ & 7 & 4.0 & \\
Total & 175 & 100.0 & \\
\hline
\end{tabular}


This study included 175 patients who were undergone Pap test, VIA and biopsy for screening of pre-invasive carcinoma of cervix. The age range $20-55$ years \& the mean age ( $\pm 2 \mathrm{SD}$ ) was $36.0 \pm 16.0$ years

Table II: Result of cytology:

\begin{tabular}{lcc}
\hline $\begin{array}{l}\text { Cytology } \\
\text { report }\end{array}$ & Frequency & Percentage \\
\hline Normal & 53 & 30.3 \\
Inflammatory & 84 & 48.0 \\
Dysplasia: & 38 & 21.7 \\
Mild & 19 & 10.9 \\
Moderate & 10 & 5.7 \\
Severe & 9 & 5.1 \\
\hline Total & 175 & 100 \\
\hline
\end{tabular}

Out of all patients 53 (30.3\%) had normal Pap smear reports, $84(48.0 \%)$ had inflammatory findings and rests 38 (21.7\%) had dysplasia (mild $10.9 \%$, moderate $5.7 \%$ \& severe $5.1 \%$ )

Table III: Result of VIA:

\begin{tabular}{ccc}
\hline VIA Finding & Frequency & Percentage \\
\hline Positive & 53 & 30.3 \\
Negative & 122 & 69.7 \\
Total & 175 & 100
\end{tabular}

Out of all patients 53 (30.3\%) had VIA positive and 122 (69.7\%) had VIA negative findings

Table VI: findings of Pap's VIA and biopsy

\begin{tabular}{llcc}
\hline Tests reports & $\begin{array}{l}\text { Frequen } \\
\text { cy }\end{array}$ & Percent \\
\hline Pap's & Positive & 38 & 21.7 \\
reports: & Negative & 137 & 78.3 \\
VIA & Positive & 53 & 30.3 \\
Findings & Negative & 122 & 69.7 \\
Biopsy: & Positive & 41 & 23.4 \\
& Negative & 134 & 76.6 \\
\hline
\end{tabular}

Table VII: Correlation of Cytology findings and biopsy reports $(\mathrm{n}=175$

\begin{tabular}{|c|c|c|c|}
\hline \multirow{2}{*}{$\begin{array}{c}\text { Pap } \\
\text { reports }\end{array}$} & \multicolumn{2}{|c|}{ Biopsy } & \multirow[t]{2}{*}{ Total } \\
\hline & Positive & Negative & \\
\hline \multirow[t]{2}{*}{ Positive } & 33 & 8 & 38 \\
\hline & $\begin{array}{c}\text { True (+)ve } \\
\text { (TP) }\end{array}$ & $\begin{array}{c}\text { False (+)ve } \\
\text { (FP) }\end{array}$ & \\
\hline \multirow[t]{2}{*}{ Negative } & 8 & 129 & 137 \\
\hline & $\begin{array}{c}\text { False (-)ve } \\
(\text { FN) }\end{array}$ & $\begin{array}{l}\text { True (-)ve } \\
\text { (TN) }\end{array}$ & \\
\hline Total & 41 & 134 & 175 \\
\hline
\end{tabular}

Sensitivity $=\mathrm{TP} /(\mathrm{TP}+\mathrm{FN})$;

Specificity $=\mathrm{TN} /(\mathrm{FP}+\mathrm{TN})$;

$\mathrm{PPV}=\mathrm{TP} /(\mathrm{TP}+\mathrm{FP})$;

$\mathrm{NPV}=\mathrm{TN} /(\mathrm{FN}+\mathrm{TN})$

Accuracy $=(\mathrm{TP}+\mathrm{TN}) /(\mathrm{TP}+\mathrm{FP}+\mathrm{FN}+\mathrm{TN})$

Table VIII: Correlation of VIA findings and biopsy reports $(\mathrm{n}=175)$

\begin{tabular}{lccc}
\hline $\begin{array}{l}\text { VIA } \\
\text { reports }\end{array}$ & Positive & $\begin{array}{c}\text { Biopsy } \\
\text { Negative }\end{array}$ & Total \\
\hline Positive & 37 & 16 & 53 \\
& $\begin{array}{c}\text { True }(+) \text { ve } \\
\text { (TP) }\end{array}$ & $\begin{array}{c}\text { False (+)ve } \\
(\mathrm{FP})\end{array}$ & \\
Negative & $\begin{array}{c}118 \\
\text { False (-)ve } \\
(\mathrm{FN})\end{array}$ & $\begin{array}{c}\text { True (-)ve } \\
(\mathrm{TN})\end{array}$ & 122 \\
& 41 & 134 & 175 \\
\hline Total & & &
\end{tabular}

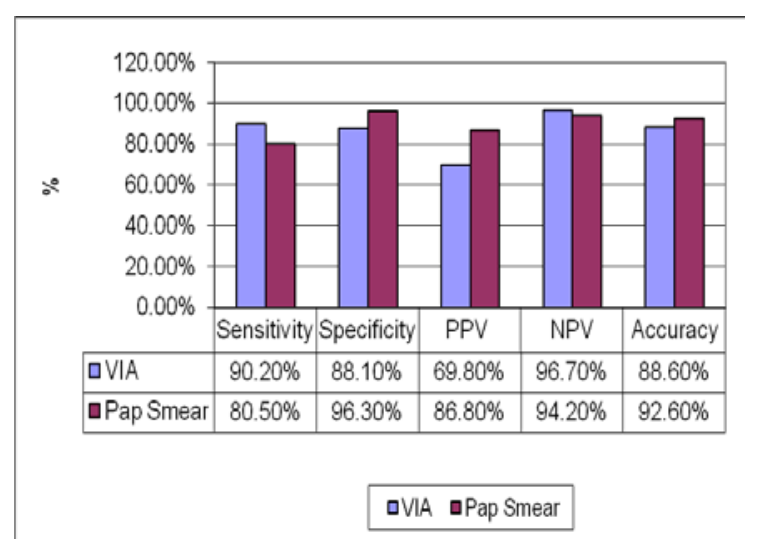

Figure 2: Validity of screening test in detecting dysplastic lesion of uterine cervix.

Among the validity test the Sensitivity, specificity, PPV, NPV and accuracy of VlA and Pap smear 
reports were $90.20 \%, 88.10 \%, 69.80 \%, 96.70 \%$, $88.6 \%$. and $80.50 \%, 96.30 \%, 86.80 \%, 94.20 \%$, $92.60 \%$ respectively

Table-X: Comparison of diagnostic values of VIA \& Pap smear by other studies:

\begin{tabular}{|l|c|c|c|c|c|}
\hline Study & Screening test & Sensitivity (\%) & $\begin{array}{c}\text { Specificity } \\
(\%)\end{array}$ & $\begin{array}{c}\text { PPV } \\
\text { (\%) }\end{array}$ & $\begin{array}{c}\text { NPV } \\
\text { (\%) }\end{array}$ \\
\hline Present Study & VIA & 90.2 & 88.1 & 69.8 & 96.7 \\
& Pap smear & 80.5 & 96.3 & 86.8 & 94.2 \\
\hline Basu et al. & VIA & 55.7 & 82.1 & 6.2 & 98.9 \\
(2003) & Pap smear & 29.5 & 92.3 & 7.9 & 98.3 \\
\hline Hegde et al. & VIA & 70.8 & 95.0 & 62.9 & 96.5 \\
(2011) & Pap smear & 83.0 & 98.0 & 80.0 & 97.9 \\
\hline Rana et al. & VIA & 93.0 & 90.0 & 62.5 & 98.0 \\
(2010) & Pap smear & 83.0 & 97.0 & 83.0 & 97.0 \\
\hline Bhatla et al. & VIA & 100.0 & 53.3 & 15.7 & 100.0 \\
(2007) & Pap smear & 62.5 & 94.7 & 50.0 & 96.07 \\
\hline Ghaemmaghami & VIA & 74.0 & 94.0 & 68.1 & 95.5 \\
et al. (2003) & Pap smear & 72.0 & 90.2 & 55.7 & 94.9 \\
\hline
\end{tabular}

\section{Discussion}

In our study, 175 women who attended department of Obstetrics \& Gynecology outdoor in Rajshahi Medical college Hospital with various presenting symptoms .Similar studies were performed at different hospital in different countries. Goel et al. $(2005)^{5}$ examined 400 women, Hegde et al. $(2011)^{6}$ conducted about225 pts, Ghaemmaghami et al. (2003) ${ }^{1}$ compared VIA with pap smear about 1200 eligible women. Tayyeb et al. (2003) ${ }^{7}$ examined 540 women. JHPIEGO (1999) $)^{8} 10934$ women were screened in 2 phase.

In this study 20-55 age group women were involved, study done by Goel et al. ${ }^{5}$ took 30-34 age group whereas Hegde et al. ${ }^{6}$ conducted women age 20- 55 \& Denny $\mathrm{L}^{9}$ conducted screening program in 35-65 age. In our study patient were attended with common complaints of per vaginal discharge as foul smell, blood stain discharge, discharge with itching, post coital bleeding, post menopausal bleeding etc. All the women were married \& majorities were sexually active. Maximum participants were house wife \& middle to lower economic class. Per speculum examination of cervix in this study showed some apparently healthy, some ectropion, hypertrophied, oedematous \& some had nabothian cyst.
This type of study was multi disciplinary approach and different study done by different way involved Gynecologist, pathologist, Oncologist. In this study VIA, Pap smear, Biopsy all done by gynecologist, study conducted by Bhatla et al. ${ }^{3}$, Goel et al. ${ }^{5}$, Hegde et al. $^{6}$ a gynecologist performed the procedure. In contrast trained nurses \& midwives were also involved in few studies. This study compared VIA with Pap smear with gold standered method biopsy but other study like Hegde et al. ${ }^{6}$ compared VIA with Pap smear with colposcopy guided biopsy only +ve cases, Sankaranarayanan et al. ${ }^{10}$ study VIA with cytology $\&+$ ve cases only biopsy, Basu et al. ${ }^{11}$ evaluated the performance of VIA, VIAM, \& cytology with biopsies all patients, Goel et al. ${ }^{5}$ used VIA, cytology \& colposcopy, in addition they also done LLETZ (large loop excision of transformation zone) instead of biopsy. Khan $S$ et al. ${ }^{2}$ VILI ( visual inspection with Lugols Iodine), VIA \& cytology done \& +ve cases sent for colposcopy guided biopsy. In this study VIA test as a screening test to detect pre invasive carcinoma of cervix compared with Pap smear test. From 175 cases 53(30.3\%) were VIA +ve \& 38(21.7\%) had abnormal pap smear test. In many literature reviews, we found minimum variation. In Sankaranarayanan et al. (1998) ${ }^{10}$ study 9.9\% VIA 
+ve \& 16.2\% abnormal pap smear. IN another study Serian et al. (2005) ${ }^{12}$ VIA were $11.6 \%$ +ve \& Pap smear were $2.2 \%$ abnormal. In study done by Rana et al. (2010) ${ }^{13} 24 \%$ were VIA +ve \& $12 \%$ were pap +ve. In Ghaemmaghanni et al. (2004) ${ }^{1}$ study $16.1 \%$ of patients were VIA +ve \& $19 \%$ were Pap smear +ve. Hegde et al. $(2011)^{6}$ studies VIA was +ve 27(12\%) \& Pap smear was 26(11.7\%).

Differences in that population might be the reason for these differences in the results of the tests. The wide range is due to difference in interpretation, since few studies used nurses, paramedical and also other health workers to do the test. It also depends on the study population since few studies were done on symptomatic hospital based population and others as a mass screening test. Rajshahi Medical College Hospital is a referral hospital so it might be acceptable if consider our subjects as a high risk population and there would be more abnormal screening test results compared to general population.

VIA test compared to Pap smear had a higher value of sensitivity and NPV, lower value of specificity and PPV and similar value in case of accuracy in our study. Its sensitivity was $90.2 \%$ compared to Pap smear $80.5 \%$. Specificity of VIA was $88.1 \%$ and for Pap smear this was $96.3 \%$ and PPV of VIA $69.8 \%$ and Pap smear $86.8 \%$, NPV of VIA was $96.7 \%$ and Pap smear was $94.2 \%$. In our study accuracy of VIA was $88.6 \%$ and Pap smear was $92.6 \%$.

Comparison of diagnostic values of VIA and Pap smear by some other studies is shown in table no10 . This study showed a higher sensitivity (90.2\%) of VIA than cytology (80.5\%) but low specificity ( $88.1 \%)$ of VIA than cytology(96.3\%). The low specificity of VIA in our study was due to a large number of inflammatory smear that showed acetowhite appearance. The wide variation in different study result lies in the number of screeners, different study setting, providers, study protocols and lack of uniform criteria. In this study chi square test was done to know the association between VIA and Pap smear findings and the result was statistically insignificant.

\section{Conclusion}

The study finds that detection rate of early lesions as moderate to severe dysplasia of cervix using VIA is comparable to Pap smear in sensitivity and specificity and usefulness. Advantage of VIA to Pap smear include higher sensitivity, low costs and immediately result that overcomes the problem of loss to follow up that occurs in cytology based program. As VIA is cheap, easy procedure, can be done in simple setup, dose not require laboratory infrastructure, procedure is noninvasive, safe \& not painful and allows women to get instant result, therefore women are willingly to accept VIA screening. So we can conclude that VIA is valid as cytology to detection of precursors of cervical cancer is a suitable screening modality for large population in low resource setting in developing countries.

\section{References}

1. Ghaemmaghami F, Modarres Gilani M, Marjani M, Mousavi A. Assessment of visual inspection with acetic acid (via) as a screening test for cervical neoplasia in comparison with cytologic screening. Acta Medica Iranica. 2003; 41(4): 248-50

2. Khan S, Jha R, Pant PR. Accuracy of cytology, visual inspection with acetic acid or lugol's iodine in cervical cancer screening. N J Obstet Gynecol. 2007; 2(2): 48-53

3. Bhatla N, Mukhopadhyay A, Joshi S, Kumar A, Kriplani A, Pandey RM. Visual inspection for cervical cancer screening; evaluation by doctor versus paramedical worker. Indian J Cancer. 2007; 41(1): 32-36

4. WHO/ICO Infonnaticn Centre on HPV and related Cancer (HPV Information Centre). Updated Summery report on HPV and cervical cancer statistics in Bangladesh. 2010. Available in www.who.int/hpvcentre

5. Goel A, Gandhi G, Batra S, Bhambhani S, Zutshi V et al. Visual inspection of the cervix with acetic acid for ervical intraepithelial lesions. Int J Gynecol Obstet. 2005; 88: 25-30

6. Hegde D, Shetty $H$, Shetty $P$ K, Rai S, Manjeera L, Vyas N. Diagnostic value of VIA comparing with conventional pap smear in the detection of colposcopic biopsy proved CIN. K S Hegde Medical Academy, Karnataka, India. 2011; 9: 134-39

7. Tayyeb R, Khawaja NP, Malik N. Comparison of visual inspection of cervix and Pap smear for cervical cancer screening. J Coll Physicians Surg Pak. 2003; 3(4): 201-3 
8. University of Zimbabwe/JHPIEGO Cervical Cancer Project. Visual inspection with cervical cancer screening: test qualities in primary-care setting. Lancet.1999; 353: 869-73

9. Denny L. Evaluation of alternative methods of cervical cancer screening for resource-poor setting. Cancer.2000; 89: 826-33

10. Sankaranarayanan $R$, Wesley $R$, Somanathan $T$, Dhakad N, Shyamalakumary B, Amma NS, Parkin $M$, Nair MKVisual inspection of the uterine cervix after the application of acetic acid in the detection of cervical carcinoma and its precursors. Cancer. 1998; 83(10): 2150-6

11. Basu PS, Sankaranayanan R, Andal R, Roy C, Das $P$, Choudhury D. Visual inspection with acetic acid and cytology in the early detection of cervical neoplasia in Kolkata, India', Int $\mathrm{J}$ Gynecol Cancer.2003;13(5): 626-32

12. Sarian LO, Derchain SF, Naud P, Roteli-Martins C, Longatto-Filho $A$, Tatti $S$. Evaluation of visual inspection with acetic acid (VIA), Lugol's iodine (VILI), cervical cytology and HPV testing as cervical screening tools in Latin America. $J$ Med Screen. 2005; 12: 142-9

13. Rana $T$, Zia A, Sher $S$, Tariq $S$, Asghar $F$. Comparative Evaluation of PAP Smear and Visual Inspection of Acetic Acid (VIA) in Cervical Cancer Screening Program in Lady Willingdon Hospital, Lahore. 2010;16(1): 104-7
All correspondence to Dr. Nargis Zahan Junior Consultant Department of Obstetrics \& Gynaecology Rajshahi Medical College Hospital, Rajshahi Email: dr.chhanda1974@gmail.com 